\title{
Optimalisasi Stemming Kata Berimbuhan Tidak Baku Pada Bahasa Indonesia Dengan Levenshtein Distance
}

\author{
Rahardyan Bisma Setya Putra ${ }^{1 *)}$, Ema Utami ${ }^{2}$, Suwanto Raharjo ${ }^{3}$ \\ ${ }^{1,2}$ Magister Teknik Informatika, Universitas Amikom Yogyakarta \\ ${ }^{3}$ Teknik Informatika, Fakultas Teknologi Industri, Institut Sains \& Teknologi AKPRIND Yogjakarta \\ ${ }^{1,2}$ Condong Catur, Depok, Sleman, Yogyakarta 55281, Indonesia \\ ${ }^{3} \mathrm{Jln}$. Kalisahak No.28 Kompleks Balapan Tromol Pos 45 Yogjakarta, Indonesia \\ email: 'amsibsam@mail.com, ${ }^{2}$ ema.u@amikom.ac.id, ${ }^{3}$ wa2n@akprind.ac.id
}

Received: 30 Maret 2018; Revised: 10 Mei 2018; Accepted: 14 Mei 2018

Copyright $\odot 2018$ Politeknik Harapan Bersama Tegal. All rights reserved

\begin{abstract}
Stemming algorithm Nazief \& Andriani has been development in terms of the speed and the accuracy. One of its development is Non-formal Affix Algorithm. Non-formal Affix Algorithm improves the accuracy for non-formal affixed word. In its growth, Indonesian language is used in two ways: formal and non-formal. Non-formal language is commonly used in casual situations such as conversations and social media post (Facebook, Twitter, Instagram, etc.). To get the root of the word of a casual conversation or a social media post, stemming algorithm which can process the non-formal words with affixes already proposed. But, the previous algorithm unable to stem a non-formal word that slightly change the root word. Therefore, this study modifies Non-formal Affix Algorithm to increase stemming accuracy on non-formal word. Modifications are made by adding Levenshtein Distance. The result of the research shows that the algorithm made in this research has $96.6 \%$ accuracy while the Non-formal Affix algorithm has $73.3 \%$ accuracy in processing 60 non-formal affixed words. Based on the result, Levenshtein Distance approach can increase the accuracy on stemming non-formal affixed word.
\end{abstract}

Abstrak - Algoritma stemming Nazief \& Andriani sudah banyak dikembangkan dari sisi kecepatan maupun akurasi. Salah satu pengembangannya adalah Algoritma Non-formal Affix. Algoritma ini meningkatkan akurasi stemming pada kata berimbuhan tidak baku. Pada perkembangannya, Bahasa Indonesia digunakan dalam dua cara: baku dan tidak baku. Bahasa tidak baku biasanya digunakan pada situasi yang santai seperti percakapan santai ataupun post dan komen di sosial media (Facebook, Twitter, Instagram, dll). Untuk mendapatkan kata dasar dari kata berimbuhan tidak baku telah diusulkan sebelumnya algoritma stemming Non-formal Affix. Namun algoritma ini masih memilki keterbatasan dalam melakukan stemming kata berimbuhan tidak baku yang memiliki sedikit perubahan pada kata dasarnya. Oleh karena itu penelitian ini berfokus pada modifikasi algoritma Non-formal Affix untuk meningkatkan akurasinya dalam stemming kata berimbuhan tidak baku. Hasil dari penelitian ini menunjukkan bahwa hasil modifikasi dengan Levenshtein Distance memiliki tingkat akurasi 96.6\%, sedangkan algoritma Non-formal Affix memiliki akurasi $73.3 \%$ pada saat stemming 60 kata berimbuhan tidak baku. Sehingga dapat disimpulkan bahwa pendekatan dengan Lenshtein Distance dapat meningkatkan akurasi algoritma Non-

*) Corresponding author: Rahardyan Bisma Setya Putra Email: amsibsam@gmail.com formal Affix dalam melakukan stemming kata berimbuhan tidak baku.

Kata Kunci - Natural Language Processing, Stemming, Levenshtein Distance, Similarity.

\section{PENDAHULUAN}

Bahasa Indonesia dapat digunakan secara formal maupun non-formal. Penggunaan Bahasa non-formal di Indonesia biasanya dilakukan pada kondisi yang santai misalnya seperti pada saat chat, komentar di media sosial, atau post di media sosial seperti. Orang Indonesia cenderung menggunakan Bahasa non-formal seperti pada cuitan yang diambil dari twitter. Salah satunya adalah "Lu ga bakal bias nemuin rekamannya, ini khusus" kata "nemuin" dimana kata formalnya adalah "menemukan" dengan kata dasar "temu". Twitter dapat menyediakan data dengan jumlah yang besar dan mudah didapat [15]. Sehingga akan banyak dilakukan pengolahan data yang bersumber dari twitter yang dimana kebanyakan masyarakat Indonesia menggunakan Bahasa tidak baku.

Pada penelitian sebelumnya dengan judul "Non-formal Affixed Word Stemming In Indonesian Language" menghasilkan modifikasi algoritma stemming Nazief \& Andriani dengan improvisasi Flexible Affix Classification dari Reina Setiawan [1]. Penelitian sebelumnya ini berfokus pada modifikasi algoritma stemming Bahasa Indonesia agar dapat melakukan stemming pada kata berimbuhan tidak baku [2].

Stemming dapat diterapkan sebagai text processing, seperti information retrieval, pengecekan plagiarism, peningkatan performa pencarian, dan lainnya $[3,4,5,6]$. Stemming pada kata tidak baku dapat dimanfaatkan sebagai bagian dari proses sentiment analysis, chat bot, dan pemrosesan teks lainnya [2]. Pada penelitian sebelumnya stemming Nonformal Affix masih memiliki keterbatasan. Algoritma Nonformal Affix tidak dapat melakukan stemming pada kata berimbuhan tidak baku yang kata dasarnya sedikit berubah seperti "Critain" dengan kata dasarnya adalah "Cerita".

Berdasarkan pada masalah yang ada pada penelitian sebelumnya, maka penelitian ini akan melakukan modifikasi pada algoritma Non-formal Affix agar dapat melakukan stemming pada kata berimbuhan tidak baku yang kata dasarnya sedikit berubah. Dengan saran dari penelitian 
sebelumnya, maka pendekatan menggunakan algoritma edit distance (Levenshtein) untuk menghitung kemiripan kata dasar yang ada pada dictionary dengan kata dasar yang sedikit berubah. Edit distance dipropos oleh ilmuan Rusia Vladimir Levenshtein pada tahun 1965 [7]. Algoritma Levenshtein adalah pengukur kemiripan antara dua string [8]. Diharapkan modifikasi ini dapat meningkatkan akurasi dari algoritma Non-formal Affix dalam melakukan stemming kata berimbuhan tidak baku.

\section{PENELITIAN YANG TERKAIT}

Banyak penelitian yang mengembangkan atau menggunakan stemming. Salah satu algoritma stemming pada Bahasa Indonesia yang banyak dikembangkan adalah algoritma Nazief \& Andriani. Flexible Affix Classification meningkatkan performa algoritma Nazief \& Andriani dalam melakukan stemming kata yang berulang seperti "berlarilari", "bersalam-salaman". Dari 1704 text pada dokumen yang di stemming menunjukkan bahwa algoritma ini memiliki hasil akurasi yang lebih baik. Penelitian tersebut dilakukan oleh Setiawan, Kurniawan, Budiharto, Kartowisastro, dan prabowo [1]. Algoritma Nazief \& Andriani juga digunakan sebagai retrieval system dalam $\mathrm{Al}$ Hadth pada Bahasa Indonesia oleh Atqia Aulia, Dewi Khairani, dan Nashrul Hakiem [9]. Pada penelitian ini dilakukan penggabungan teknik stemming Nazief \& Andriani dengan Bahasa pemrogramman PHP untuk menampilkan hasil pencarian hadis. Penelitian tersebut menghasilkan 1 recall score dan precision $96.1 \%$.

Asian, William, dan Tahaghohhi mengembangkan teknik confix-stripping pada algoritma Nazief \& Andriani [10]. Penelitian tersebut menghasilkan peningkatan akurasi dari Nazief \& Andriani 93\% menjadi 95\%. Confix-stripping juga dilakukan oleh Arifin, Mahendra, dan CIptaningtyas [11]. Penelitian tersebut sukses meningkatkan pengurangan term size menjadi $32.66 \%$ dari sebelumnya adalah $30.95 \%$. Rahardyan dan Ema Utami mengembangkan algoritma Nazief \& Andriani dengan menambahan Non-formal Affix rule agar algoritma Nazief \& Andrian dapat melakukan stemming pada kata berimbuhan tidak baku [2]. Penelitian tersebut berhasil meningkatkan akurasi dari algoritma Nazief \& Andriani dalam melakukan stemming kata tidak baku dari 35\% menjadi $73.3 \%$. Namun pada penelitian tersebut masih terdapat beberapa kegagalan hasil stemming yang dikarenakan kata berimbuhan tidak baku yang sedikit merubah kata dasarnya. Oleh karena itu penelitian yang akan dilakukan saat ini adalah memodifikasi algoritma non-formal affix dengan pendekatan Levenshtein Distance agar dapat meningkatkan akurasi dalam melakukan stemming kata berimbuhan tidak baku

\section{METODE PENELITIAN}

\section{A. Tahapan Penelitian}

Penelitian yang dilakukan berfokus pada modifikasi algoritma Non-formal Affix dengan melakukan penambahan pendekatan string similarity menggunakan algoritma Levenshtein Distance. Alur penelitian dapat dilihat pada Gbr. 1.

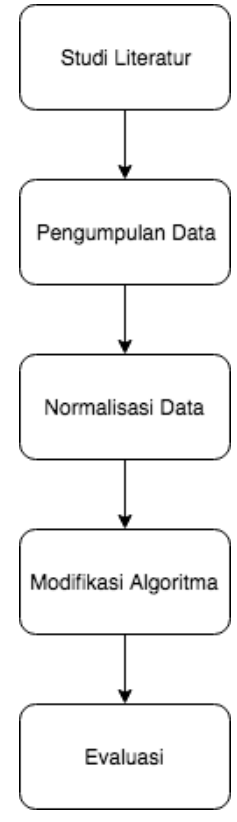

Gbr. 1 Alur penelitian

1) Melakukan studi literatur untuk memperdalam pengetahuan dan mencari landasan teori mengenai struktur imbuhan pada Bahasa Indonesia, imbuhan tidak baku, stemming, dan levenshtein distance.

2) Data merupakan jenis sekunder yang diambil dari penelitian sebelumnya yang berjudul "Non-formal Affixed Word Stemming in Indonesian Language" [2] dari sumber pertama dari penelitian "Afiks Tidak Baku dalam Bahasa Indonesia Ragam Informal” [14].

3) Data dinormalisasi ke dalam bentuk yang kompatibel untuk dilakukan proses dalam Bahasa pemrogramman.

4) Melakukan modifikasi algoritma pada penelitian "Nonformal Affixed Word Stemming in Indonesian Language" dengan melakukan penambahan pendekatan Levenshtein Distance. Cara kerja dapat dilihat pada Gbr 4.

5) Dilakukan evaluasi untuk mengukur tingkat akurasi dari hasil modifikasi algoritma yang ditambahkan pendekatan Levenshtein Distance. Evaluasi dilakukan dengan cara membandingkan persentase keberhasilan antara algoritma Non-formal Affix dengan algoritma yang sudah dimodifikasi dengan Levenshtein Distance.

\section{B. Struktur Imbuhan Bahasa Indonesia}

Pada penelitian sebelumnya dikembangkan algoritma dengan algoritma dasar yaitu Nazief \& Andriani. Pengembangan yang dilakukan menggunakan meningkatkan akurasi algoritma Nazief \& Andriani untuk melakukan stemming pada kata berimbuhan tidak baku. Berdasar penelitian sebelumnya, struktur imbuhan bahasa Indonesia terdiri dari prefiks, infiks, sufiks, konfiks, dan simulfiks [2]. Struktur imbuhan pada Bahasa Indonesia dapat dilihat pada Gbr. 2. 


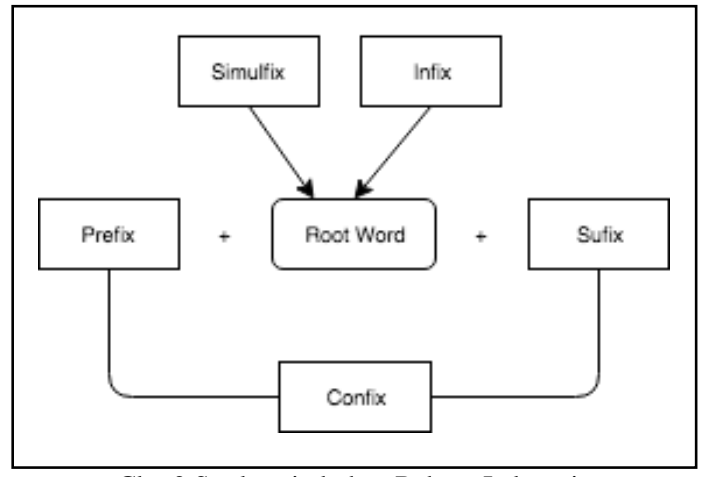

Gbr. 2 Struktur imbuhan Bahasa Indonesia

1) Prefiks: Prefiks adalah afiks yang diletakkan di depan sebuah kata dasar. Menurut S. Takdir Alisjahbana di dalam Khotimah, prefiks $d i-$, ke-, ter-. Memiliki kegunaan untuk menyatakan tempat dan bentuk positif [12]. Example: me- (menjual), ke-(kedepan), ter-(termakan), per- (perkuda), se-(sebagai), ber-(berjalan).

2) Sufiks: Sufiks merupakan afiks yang diletakkan di bagian belakang kata dasar [12]. E.g.: -an (makanan), - $i$ (manusiawi), wi merupakan perubahan bunyi dari sufiks $-i$.

3) Infiks: Merupakan afiks yang diletakkan di dalam kata dasar [12]. E.g.: -le (gelembung), -em(gemetar), -er (gerigi).

4) Simulfiks: Simulfiks adalah afiks yang menggantikan huruf di depan suatu kata. Afiks ini berfungsi untuk membentuk kata kerja dari suati kata dasar [12]. E.g.: soto (Indonesian food) $\Rightarrow$ nyoto (eating soto), sate (Indonesian food) $=>$ nyate (eating sate).

5) Konfiks: Konfiks merupakan kombinasi dari prefiks dan sufiks untuk membentuk kata baru yang berasal dari kata dasar [1]. E.g.: meng- -kan (menggunakan), di- per- -kan (dipertemukan).

\section{Levenshtein Distance}

Salah satu metode yang digunakan untuk menentukan tingkat kemiripan antar string adalah Levenshtein Distance. Metode ini merupakan metode yang klasik dan mudah digunakan [research on]. Cara kerja dari metode ini adalah dengan menghitung seberapa banyak langkah yang dibutuhkan oleh string A untuk bisa menjadi string B. Semakin sedikit langkah yang dibutuhkan, maka kedua string tersebut semakin memiliki tingkat kemiripan yang tinggi [13]. Dapat dicontohkan kemiripan antara kata "Teman" dan "Temen", maka dari "Teman" untuk menjadi "Teman" dibutuhkan 1 perubahan huruf "e" pada huruf urutan ke. Sehingga jarak kemiripan antara "Teman" dengan "Teman" adalah 1. Contoh berhitungan Levenshtein dapat dilihat pada Tabel 2.

\section{Data Kata Berimbuhan Tidak Baku}

Dalam Bahasa Indonesia selain bahasa baku terdapat juga bahasa yang tidak baku yang sering digunakan dalam percakapan tidak resmi. Bahasa Indonesia memiliki variasai pemakaian dalam situasi tertentu, yaitu resmi dan tidak resmi [14]. Berdasarkan penelitian Zen [14] terdapat beberapa kata berimbuhan tidak baku. Data kata berimbuhan tidak baku diambil dari penelitian sebelumnya [2], berdasar pada penelitian Zen [14] yang dapat dilihat pada Tabel 1. Kata-kata berimbuhan tidak baku masing-masing memiliki fungsi dalam membentuk kata kerja, kata benda, dan kata sifat [14].

TABEL I

MATRIKS PERHITUNGAN JARAK LEVENHSTEIN

\begin{tabular}{|l|l|l|l|l|l|l|}
\multicolumn{1}{c|}{} & & $\mathbf{t}$ & $\mathbf{e}$ & $\mathbf{m}$ & $\mathbf{a}$ & $\mathbf{n}$ \\
\hline & $\mathbf{0}$ & 1 & 2 & 3 & 4 & 5 \\
\hline $\mathbf{t}$ & 1 & $\mathbf{0}$ & 1 & 2 & 3 & 4 \\
\hline $\mathbf{e}$ & 2 & 1 & $\mathbf{0}$ & 1 & 2 & 3 \\
\hline $\mathbf{m}$ & 4 & 2 & 1 & $\mathbf{0}$ & 1 & 2 \\
\hline $\mathbf{e}$ & 5 & 3 & 2 & 1 & 1 & 2 \\
\hline $\mathbf{n}$ & 6 & 4 & 3 & 2 & 2 & $\mathbf{0}$ \\
\hline
\end{tabular}

TABEL II

DAFTAR KATA BERIMBUHAN TIDAK BAKU

\begin{tabular}{|c|c|c|}
\hline Bentuk dasar & Bentuk tidak baku & $\begin{array}{c}\text { Stemming Informa } \\
\text { Affix }\end{array}$ \\
\hline Terjang & Nerjang & Terjang \\
\hline Tuduh & Nuduh & Tuduh \\
\hline Terima & Nerima & Terima \\
\hline Tegur & negur & Tegur \\
\hline Pukul & mukul & Pukul \\
\hline Pimpin & Mimpin & Pimpin \\
\hline Coba & nyoba & Coba \\
\hline Siram & nyiram & Siram \\
\hline Suruh & Nyuruh & Suruh \\
\hline Simpan & Nyimpen & Nyimpen \\
\hline Sebrang & Nyebrang & Nyebrang \\
\hline Anggap & Nganggep & Nganggep \\
\hline Amuk & Ngamuk & Amuk \\
\hline Ambil & Ngambil & Ambil \\
\hline Buka & Ngebuka & Buka \\
\hline Bantu & Ngebantu & Bantu \\
\hline Lepas & Ngelepas & Lepas \\
\hline Bayang & Kebayang & Bayang \\
\hline Injak & Keinjek & Keinjek \\
\hline Kabul & Kekabul & Kabul \\
\hline Pergok & Kepergok & Pergok \\
\hline Tipu & Ketipu & Tipu \\
\hline Ulang & Keulang & Ulang \\
\hline Wujud & Kewujud & Wujud \\
\hline Crita & Critain & Critain \\
\hline Betul & Betulin & Betul \\
\hline Manja & Manjain & Manja \\
\hline Ganggu & Gangguin & Ganggu \\
\hline Ganti & Gantian & Ganti \\
\hline Ikut & Ikutan & Ikut \\
\hline Musuh & Musuhan & Musuh \\
\hline Sabun & Sabunan & Sabun \\
\hline Teman & Temenan & Temenan \\
\hline
\end{tabular}




\begin{tabular}{|c|c|c|}
\hline Tukar & Tukeran & Tukeran \\
\hline Tanya & nanyain & Tanya \\
\hline Tunjuk & nunjukin & Tunjuk \\
\hline penting & mentingin & Ting \\
\hline Pegang & megangin & Pegang \\
\hline Selamat & nyelametin & Nyelametin \\
\hline Sempat & nyempetin & nyempetin \\
\hline Korban & ngorbanin & Ngorbanin \\
\hline Hadap & ngadepin & Ngadepin \\
\hline Bukti & ngebuktiin & Bukti \\
\hline Warna & ngewarnain & Warna \\
\hline Dengar & Kedengeran & Kedengeran \\
\hline Ketemu & ketemuan & Ketemu \\
\hline Benar & beneran & Beneran \\
\hline Begini & ginian & Ginian \\
\hline Kawin & kawinan & Kawin \\
\hline Main & mainan & Main \\
\hline Pargir & parkiran & Parkir \\
\hline Dulu & duluan & Dulu \\
\hline Gendut & gendutan & Gendut \\
\hline Karat & karatan & Karat \\
\hline Paling & palingan & Paling \\
\hline Sabar & sabaran & Sabar \\
\hline Bagus & kebagusan & Bagus \\
\hline Sana & sanaan & Sana \\
\hline Cepat & cepetan & Cepetan \\
\hline pagi & sepagian & Pagi \\
\hline
\end{tabular}

\section{E. Modifikasi Algoritma dengan Levenshtein Distance}

Pada penelitian sebelumnya yang berjudul "Non-formal Affixed Word Stemming in Indonesian Language" oleh Rahardyan Bisma dan Ema Utami [2], dilakukan modifikasi algorima Nazief \& Andriani yang sudah ditingkatkan menggunakan flexible affix classification oleh Reina Setiawan [1] dengan penambahan aturan imbuhan tidak baku. Berikut dapat dilihat alur algoritma dari non-forma affix pada Gbr. 3.

TABEL III

KATA BERIMBUHAN TIDAK BAKU YANG TIDAK DAPAT DI-STEMMING PADA ALGORITMA NON-FORMAL AFFIX

\begin{tabular}{|c|c|c|}
\hline Bentuk dasar & Bentuk tidak baku & Stemming Informal Affix \\
\hline Simpan & Nyimpen & Simpen $=>$ Nyimpen \\
\hline Seberang & Nyebrang & Sebrang $=>$ Nyebrang \\
\hline Anggap & Nganggep & Anggep $=>$ Nganggep \\
\hline Injak & Keinjek & Injek $=>$ Keinjek \\
\hline Crita & Critain & Crita $=>$ Critain \\
\hline Teman & Temenan & Temen $=>$ Temenan \\
\hline Tukar & Tukeran & Tuker $=>$ Tukeran \\
\hline penting & mentingin & Ting \\
\hline Selamat & nyelametin & Selamet $=>$ Nyelametin \\
\hline Sempat & nyempetin & Sempet $=>$ nyempetin \\
\hline Korban & ngorbanin & Ngorbanin \\
\hline Hadap & ngadepin & Hadep $=>$ Ngadepin \\
\hline Dengar & Kedengeran & Denger $=>$ Kedengeran \\
\hline Benar & beneran & Bener $=>$ Beneran \\
\hline Begini & ginian & Ginian \\
\hline Cepat & cepetan & Cepet $=>$ Cepetan \\
\hline
\end{tabular}

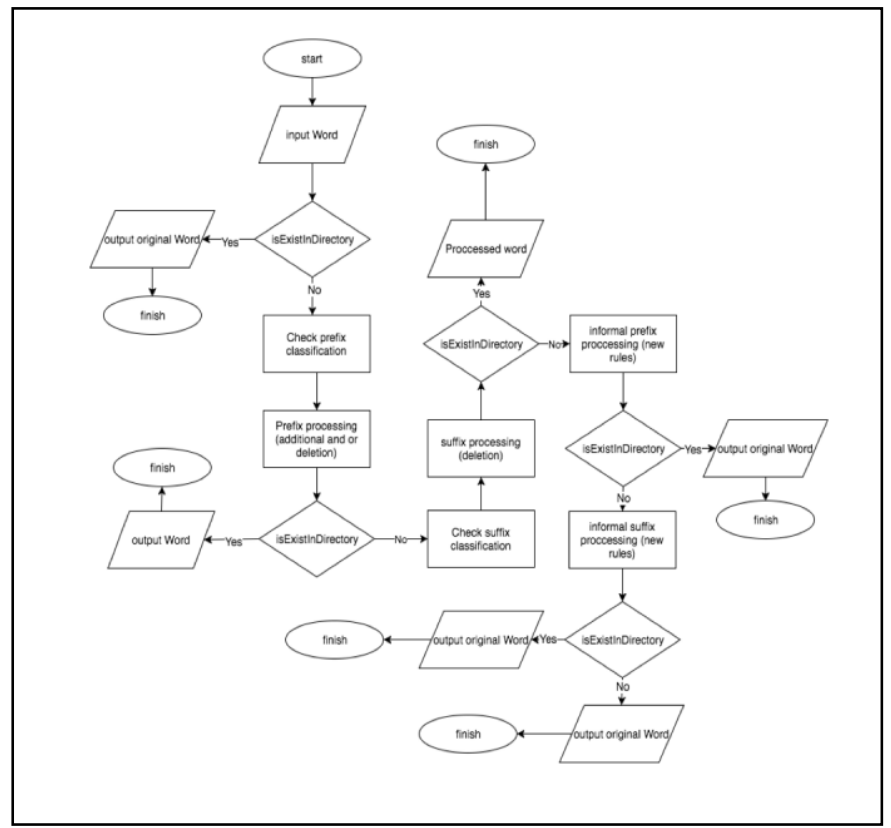

Gbr. 3 Algoritma dari Non-formal Affix

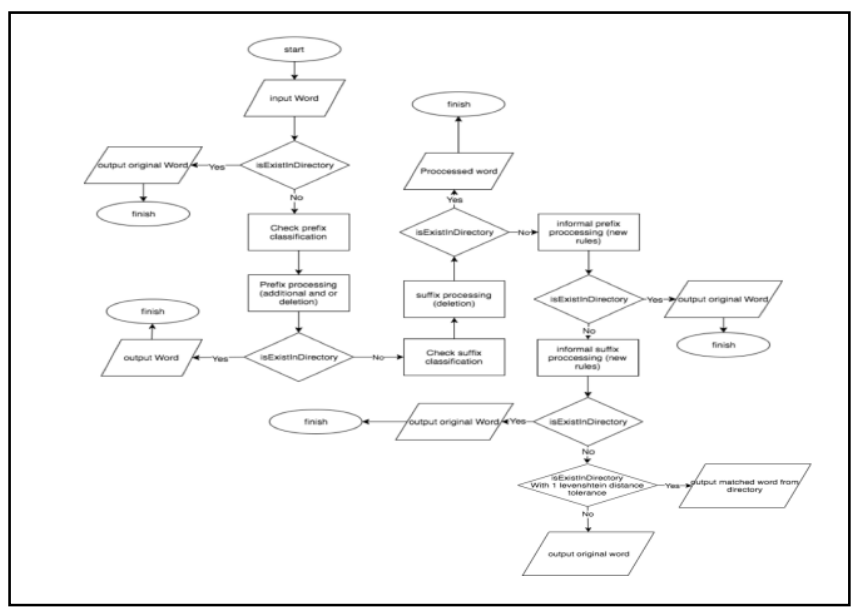

Gbr. 4 Algoritma Non-formal affix dengan Levenshtein

Dengan metode yang diusulkan, maka alur algoritma dimodifikasi dengan pendekatan Levenshtein Distance. Pengecekan kemiripan antar string dilakukan setelah seluruh proses pada algoritma Non-formal Affix selesai melakukan proses stemming dan gagal. Ketika Non-formal Affix gagal dalam melakukan stemming kata berimbuhan tidak baku, maka dilakukan pengecekan kemiripan antara kata yang 
sudah dioleh oleh algoritma Non-formal Affix dengan kata yang berada dalam kamus menggunakan Levenshtein Distance. Pada algoritma Non-formal Affix terdapat beberapa kata yang tidak berhasil di stemming yang dapat dilihat pada Tabel 3.

Dari 16 kata yang tidak berhasil di stemming 13 di antaranya tidak dapat di-stemming karena jarak kemiripan antara kata dasar yang seharusnya dengan kata dasar hasil stemming adalah 1 (penghilangan, penambahan atau penggantian 1 karakter pada kata). Karena mengalami perubahan maka kata dasar hasil dari stemming tidak ditemukan dalam kamus kata dasar. Dari data pada Tabel 3 maka pada metode yang diusulkan kata hasil stemming akan dicocokan dengan kata pada kamus dengan toleransi jarak kemiripan yaitu 1 . Sehingga algoritmanya terlihat seperti pada Gbr. 4.

\section{F. Evaluasi}

Kedua algoritma diimplemetasikan pada bahasa pemrogramman Jawa. Kata berimbuhan tidak baku dimasukkan pada Array String. Kemudian setiap kata pada array di-stemming satu per satu menggunakan perulangan. Hasil stemming dicetak pada console log yang kemudian di masukkan pada tabel perbandingan seperti pada Tabel 4.

TABEL IV

HASIL STMMING ALGORITMA NON-FORMAL AFFIX DAN NON-FORMAL AFFIX DENGAN LEVENSHTEIN

\begin{tabular}{|c|c|c|c|}
\hline Kata Dasar & $\begin{array}{c}\text { Bentuk tidak } \\
\text { baku }\end{array}$ & $\begin{array}{c}\text { Non-formal Affix } \\
\text { Levenshtein } \\
\text { Algorithm } \\
\end{array}$ & $\begin{array}{c}\text { Non-formal Affix } \\
\text { Algorithm }\end{array}$ \\
\hline Terjang & Nerjang & Terjang & Terjang \\
\hline Tuduh & Nuduh & Tuduh & Tuduh \\
\hline Terima & Nerima & Terima & Terima \\
\hline Tegur & negur & Tegur & Tegur \\
\hline Pukul & mukul & Pukul & Pukul \\
\hline Pimpin & Mimpin & Pimpin & Pimpin \\
\hline Coba & nyoba & Coba & Coba \\
\hline Siram & nyiram & Siram & Siram \\
\hline Suruh & Nyuruh & Suruh & Suruh \\
\hline Simpan & Nyimpen & Simpan & Nyimpen \\
\hline Sebrang & Nyebrang & Seberang & Nyebrang \\
\hline Anggap & Nganggep & Anggap & Nganggep \\
\hline Amuk & Ngamuk & Amuk & Amuk \\
\hline Ambil & Ngambil & Ambil & Ambil \\
\hline Buka & Ngebuka & Buka & Buka \\
\hline Bantu & Ngebantu & Bantu & Bantu \\
\hline Lepas & Ngelepas & Lepas & Lepas \\
\hline Bayang & Kebayang & Bayang & Bayang \\
\hline Injak & Keinjek & Injak & Keinjek \\
\hline Kabul & Kekabul & Kabul & Kabul \\
\hline Pergok & Kepergok & Pergok & Pergok \\
\hline Tipu & Ketipu & Tipu & Tipu \\
\hline Ulang & Keulang & Ulang & Ulang \\
\hline
\end{tabular}

\begin{tabular}{|c|c|c|c|}
\hline Wujud & Kewujud & Wujud & Wujud \\
\hline Crita & Critain & Cerita & Critain \\
\hline Betul & Betulin & Betul & Betul \\
\hline Manja & Manjain & Manja & Manja \\
\hline Ganggu & Gangguin & Ganggu & Ganggu \\
\hline Ganti & Gantian & Ganti & Ganti \\
\hline Ikut & Ikutan & Ikut & Ikut \\
\hline Musuh & Musuhan & Musuh & Musuh \\
\hline Sabun & Sabunan & Sabun & Sabun \\
\hline Teman & Temenan & Teman & Temenan \\
\hline Tukar & Tukeran & Tukar & Tukeran \\
\hline Tanya & nanyain & Tanya & Tanya \\
\hline Tunjuk & nunjukin & Tunjuk & Tunjuk \\
\hline penting & mentingin & Ting & Ting \\
\hline Pegang & megangin & Pegang & Pegang \\
\hline Selamat & nyelametin & Selamat & Nyelametin \\
\hline Sempat & nyempetin & Sempat & nyempetin \\
\hline Korban & ngorbanin & Korban & Ngorbanin \\
\hline Hadap & ngadepin & Hadap & Ngadepin \\
\hline Bukti & ngebuktiin & Bukti & Bukti \\
\hline Warna & ngewarnain & Warna & Warna \\
\hline Dengar & Kedengeran & Dengar & Kedengeran \\
\hline Ketemu & ketemuan & Ketemu & Ketemu \\
\hline Benar & beneran & Benar & Beneran \\
\hline Begini & ginian & Ginian & Ginian \\
\hline Kawin & kawinan & Kawin & Kawin \\
\hline Main & mainan & Main & Main \\
\hline Pargir & parkiran & Parkir & Parkir \\
\hline Dulu & duluan & Dulu & Dulu \\
\hline Gendut & gendutan & Gendut & Gendut \\
\hline Karat & karatan & Karat & Karat \\
\hline Paling & palingan & Paling & Paling \\
\hline Sabar & sabaran & Sabar & Sabar \\
\hline Bagus & kebagusan & Bagus & Bagus \\
\hline Sana & sanaan & Sana & Sana \\
\hline Cepat & cepetan & Cepat & Cepetan \\
\hline pagi & sepagian & Pagi & Pagi \\
\hline
\end{tabular}

\section{HASIL DAN PEMBAHASAN}

Pada penelitian ini menghasilkan algoritma stemming baru yang berdasar pada algoritma Nazief \& Andriani yang sudah dimodifikasi dengan Non-formal affix rule yang ditujukan untuk melakukan stemming pada kata berimbuhan tidak baku. Dari hasil evaluasi maka diketahui tingkat akurasi dari algoritma Non-formal Affix dalam melakukan stemming kata berimbuhan tidak baku adalah $73.3 \%$ atau 44 kata berhasil di stemming (0 understemming, 1 overstemming, 15 unstemmed). 
Dengan ditambahkannya pendekatan similarity menggunakan metode Levenshtein Distance diketahui bahwa tingkat akurasi meningkat menjadi $96.6 \%$ atau 58 kata berhasil di-stemming (0 understemming, 1 overstemming, o unstemmed). Perbandingan banyak kata yang berhasil dilakukan stemming dari Non-formal Affix dan Non-formal Affix with levenshtein dapat dilihat pada Gbr. 5.

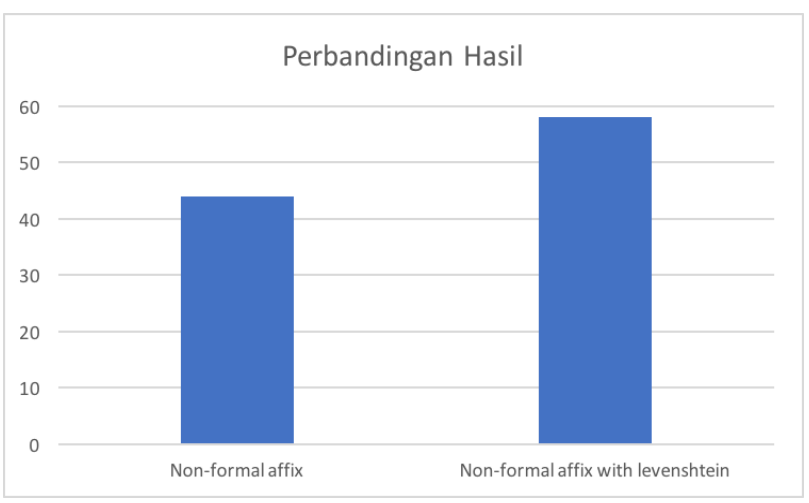

Gbr. 5 Perbandingan hasil stemming

\section{KESIMPULAN}

Dari hasil evaluasi yang sudah dilakukan dapat dilihat bahwa pendekata dengan menggunakan Levenshtein Distance dapat meningkatkan akurasi algoritma stemming Non-formal Affix dalam melakukan stemming kata berimbuhan tidak baku. Dengan pendekatan Levenshtein Distance masih belum dapat melakukan stemming pada 60 kata berimbuhan tidak baku. Kata yang tidak berhasil di-stemming adalah "ting" dikarenakan terdapat kata dasar "ting" pada dictionary dan kata "Ginian" dikarenakan belum terdapat rule yang untuk melakukan stemming kata tersebut.

Pada penelitian ini masih belum dilakukan evaluasi untuk stemming kata formal di luar 60 kata tidak baku dari data set penelitian ini. Topik ini masih memiliki peluang untuk dilakukan pengembangan kedepannya dari sisi kecepatan maupun efektifitas algoritma.

\section{DAFTAR PUSTAKA}

[1] R. Setiawan, A. Kurniawan, W. Budiharto, I. H. Kartowisastro and H. Prabowo, "Flexible affix classification for stemming Indonesian Language," 2016 13th International Conference on Electrical
Engineering/Electronics, Computer, Telecommunications and Information Technology (ECTI-CON), Chiang Mai, 2016, pp. 1-6.

[2] Rahardyan Bisma, Ema Utami, "Non-formal Affixed Word Stemming in Indonesian Language," 2018 International Conference on Information and Communication Technology (ICOIACT), Yogyakarta, 2018 .

[3] Mardiana Tari, Bharata Teguh, Hidayah Indriana, "Stemming Influence on Similiarity Detection of Abstract Written in Indonesia", in TELKOMNIKA, vol. 14, 2016, pp. 219-227.

[4] A. Aulia, D. Khairani and N. Hakiem, "Development of a retrieval system for Al Hadith in Bahasa (case study: Hadith Bukhari)," 2017 5th International Conference on Cyber and IT Service Management (CITSM), Denpasar, 2017, pp. 1-5.

[5] A. Sinaga, Adiwijaya and H. Nugroho, "Development of word-based text compression algorithm for Indonesian language document," 2015 $3 r d$ International Conference on Information and Communication Technology (ICoICT), Nusa Dua, 2015, pp. 450-454.

[6] M. K. Keleş and S. A. Özel, "Similarity detection between Turkish text documents with distance metrics," 2017 International Conference on Computer Science and Engineering (UBMK), Antalya, 2017, pp. 316321.

[7] S. Zhang, Y. Hu and G. Bian, "Research on string similarity algorithm based on Levenshtein Distance," 2017 IEEE 2nd Advanced Information Technology, Electronic and Automation Control Conference (IAEAC), Chongqing, 2017, pp. 2247-2251.

[8] A. Ene and A. Ene, "An application of Levenshtein algorithm in vocabulary learning," 2017 9th International Conference on Electronics, Computers and Artificial Intelligence (ECAI), Targoviste, 2017, pp. 1-4.

[9] A. Aulia, D. Khairani and N. Hakiem, "Development of a retrieval system for Al Hadith in Bahasa (case study: Hadith Bukhari)," 2017 5th International Conference on Cyber and IT Service Management (CITSM), Denpasar, 2017, pp. 1-5.

[10] J. Asian, H. Williams dan S. Tahaghoghi, "Stemming Indonesian", in Conferences in Research and Practice in Information Technology Series, vol. 38, 2005, pp. 307-314.

[11] A.Z. Arifin, Mahendra and Ciptaningtyas, "Enchanced confix stripping stemmer and ants algorithm for classifying news document in Indonesian language".

[12] Khotimah Khusnul, "Analysis of Indonesian Affixes in English Words Found in Mobile Guide Edition: 54-59", in Thesis in English Departmen Faculty of Humanity Diponegoro University, 2012.

[13] D. Medhat, A. Hassan and C. Salama, "A hybrid cross-language name matching technique using novel modified Levenshtein Distance," 2015 Tenth International Conference on Computer Engineering \& Systems (ICCES), Cairo, 2015, pp. 204-209.

[14] Zen Laily, "Non-formal Affix in Indonesian Informal Language Variety", in Lingua: Journal Ilmu Bahsaa dan Sastra, 2011.

[15] Emilya Ully Artha, Ahmad Dahlan, "Klasifikasi Model Percakapan Twitter Mengenai Ujian Nasional", in JPIT: Journal Pengembangan IT, 2018. 